University of South Carolina

Scholar Commons

$9-2010$

\title{
International Greenhouse Gas Offsets under the Clean Air Act
}

Nathan D. Richardson

University of South Carolina - Columbia, richarnd@law.sc.edu

Follow this and additional works at: https://scholarcommons.sc.edu/law_facpub

Part of the Environmental Law Commons

\section{Recommended Citation}

Nathan Richardson, International Greenhouse Gas Offsets under the Clean Air Act, 40 ENVTL. L. REP. News \& Analysis 10887 (2010).

This Article is brought to you by the Law School at Scholar Commons. It has been accepted for inclusion in Faculty Publications by an authorized administrator of Scholar Commons. For more information, please contact digres@mailbox.sc.edu. 


\section{International Greenhouse Gas Offsets Under the Clean Air Act}

\section{by Nathan Richardson}

Nathan Richardson is a Visiting Scholar at Resources for the Future, Washington, D.C.

\section{Editors' Summary}

Offsets, and in particular international offsets, have been advanced as an important tool in climate policy, capable of significantly reducing the costs of emissions reductions. As attention turns to the existing CAA as a potential vehicle for general reduction of GHG emissions, an important question is whether regulation under the statute is compatible with international offsets. Certain regulatory programs under the CAA are likely candidates for GHG regulation, but many of them are legally incompatible with international offsets. Those programs that might permit use of international offsets have other problems that make them unpopular choices for GHG regulation. To the extent that CAA regulation depends on state action, state law and constitutional limitations appear to offer more barriers than opportunities for use of international offsets. These conclusions have implications for the costs and flexibility of climate policy under the CAA.
$\mathrm{W}$ ith the U.S. Congress' failure to date to create comprehensive climate legislation, attention has turned to moves by the U.S. Environmental Protection Agency (EPA) to regulate greenhouse gases (GHGs) under the existing Clean Air Act (CAA). ${ }^{1}$ Among the many questions raised by this shift are whether and how policy instruments such as emissions trading and offsets can be incorporated into CAA regulation. This Article will briefly analyze whether that statute provides any plausible basis for use of international GHG offsets for stationary sources. ${ }^{2}$ The foundation for almost all of the analysis presented here is the CAA itself - no federal court rulings and very few scholarly analyses have addressed this question.

The Article briefly discusses offsets as a policy mechanism and the history of their use within the CAA, before detailing the potential for incorporation of offsets into various CAA programs that might plausibly be used for regulation of GHGs.

For various reasons discussed in detail below, none of these programs seems readily compatible with use of international offsets in the GHG context. Those programs that might be compatible are a poor fit for GHG regulation generally. Programs that are better candidates for GHG regulation contain statutory restrictions that require, at best, creative and legally questionable reinterpretation in order to be compatible with international offsets. State-level regulation under the CAA faces similar challenges and restrictions along with additional barriers that may exist in state law.

\section{Offsets and the CAA}

\section{A. Offsets as a Policy Mechanism}

Offsets are an environmental policy mechanism in which an emitter of a pollutant may increase emissions or avoid required reductions in emissions by committing to reductions in emissions elsewhere. This commitment-the offset-may come from the same facility, a different facility under the same owner, or as a result of a contractual agreement between different emitters. The general result of offset use is that emissions in the relevant area are at least no greater than before their use, but that trade offs are possible between various emitting activities and facilities. Relative to a ban on any emissions increases or individually mandated emissions reductions, offsetting should be able to achieve equivalent

Author's Note: I thank Richard Morgenstern for asking the question that inspired this Article, and Art Fraas for helpful comments and advice. All remaining errors are my own.

1. 42 U.S.C. $\$ \$ 7401-7671 \mathrm{q}$, ELR STAT. CAA \$\$101-618.

2. That is, electricity-generation plants, industrial facilities, etc. Emissions from vehicles-mobile sources—are regulated under separate CAA provisions and are not discussed here. 
environmental results at lower cost since higher value uses of a limited emissions "resource" can be prioritized.

Offsets have been recognized as a useful policy mechanism for some time, and have been a part of environmental regulation in the United States for more than 30 years. They have attracted increased interest recently due to their potentially large role in controlling the costs of GHG emissions reductions. ${ }^{3}$ Some industries and countries are able to reduce GHG emissions more cheaply than others. To the extent that emissions cuts beyond those mandated by regulations can be traded as offsets, the global cost of GHG reductions can be substantially decreased. Though some problems exist with accurately determining whether reductions are "additional" (whether they go beyond what would have been achieved anyway), offsets are generally recognized as a key part of any international effort to reduce GHG emissions. International offsets have figured prominently in climate legislation under consideration in Congress. ${ }^{4}$ Because this legislation has stalled, however, attention has partially shifted to potential regulation of GHGs by EPA under the existing CAA.

\section{B. Existing Offset Programs Under the CAA}

Offsets have been a formal part of EPA regulation at least since the 1977 Amendments to the CAA. Under the statute, EPA is charged with setting uniform national ambient air quality standards (NAAQS). ${ }^{5}$ Areas that fail to meet these standards are designated as nonattainment areas. ${ }^{6}$ Such areas are subject to strict regulation, including an effective ban on construction of major new facilities or major modifications to existing facilities that emit pollutants for which the area is above the NAAQS - unless emissions from the new or modified facility are offset. ${ }^{7}$ The Prevention of Significant Deterioration (PSD) provisions of the 1977 CAA Amendments allow such facilities to be built only if they install tight emissions controls (lowest achievable emission rate (LAER)) ${ }^{8}$ and can offset the additional emissions from the new facility with reductions elsewhere. ' These reductions can be from other facilities within the same firm, or from other firms in the same nonattainment area. ${ }^{10}$ Firms that verifiably reduce emissions beyond what is required by regulation receive emissions reduction credits (ERCs) that can be traded to firms that need to offset emissions from a new facility. ${ }^{11}$ ERCs can

3. See, e.g., Daniel S. Hall, Offsets: Incentivizing Reductions While Managing Uncertainty and Ensuring Integrity (Resources for the Future, Issue Brief CPF No. 15, Nov. 2007), available at http://www.rff.org/RFF/Documents/CPF_17_IssueBrief_15.pdf; see also Energy Info. Admin., Publ'n No. SR/OIAF/200905, Energy Market and Economic Impacts of H.R. 2454, the American Clean Energy and Security Act of 2009, at ix (2009).

4. See House Comm. on Energy \& Commerce, Summary: American Clean Energy and Security Act (H.R. 2454), at 2 (June 9, 2009), available at http:// energycommerce.house.gov/Press_111/20090724/hr2454_housesummary.pdf (identifying offsets as a major component of the Act).

5. 42 U.S.C. $\$ 7409$ (a)(1) (2007), ELR STAT. CAA \$109(a)(1).

6. CAA $\$ 107(\mathrm{~d})(1)(\mathrm{A})(\mathrm{i})$.

7. CAA $\$ 173(\mathrm{a})$.

8. CAA $\$ 171(3)$.

9. $\mathrm{CAA} \$ 173(\mathrm{c})$.

10. CAA $\$ 173(\mathrm{c})(1)$.

11. U.S. EPA, National Center for Environmental Economics: Offset Program, http://yosemite.epa.gov/ee/Epalib/incent.nsf/c484aff385a753cd85256c2c00 generally only be used within the same nonattainment area they are created. ${ }^{12}$

These ERCs and the offset program in general have become important mechanisms in regulation of nonattainment areas for the six pollutants currently regulated under the NAAQS (tropospheric ozone, nitrous oxides, sulfur dioxide, particulate matter $\left[\mathrm{PM}_{2.5}\right.$ and $\left.\mathrm{PM}_{10}\right]$, and lead). They are, however, much more limited in scope than those generally proposed in the GHG context. This is largely a reflection of the local character of the pollutants traditionally regulated under the CAA. ERCs-CAA offsets-are not tradable across the United States or internationally. They also are only relevant when CAA regulations would otherwise prevent construction of a new emitting facility - they cannot be used to avoid or mitigate the impact of regulations on emissions from existing facilities. An emitter facing, for example, a regulatory requirement to install certain control technology under the CAA cannot use an ERC to avoid having to make that investment.

\section{International Offsets Under the CAA at the Federal Level}

Given this past experience with offsets under the CAA, the need for offsets to manage the costs of international GHG regulation, and the increasing likelihood that short-term GHG regulation in the United States will be accomplished in large part through the CAA, what avenues are legally plausible for integrating international offsets into CAA GHG regulation? This section will address three such potential avenues: the CAA permitting programs (the vehicle for traditional CAA ERCs); New Source Performance Standards (NSPS) under $\$ 111$ of the CAA; and more speculative programs under CAA $\$ \$ 115$ or 615 . None of these, however, seem to provide a solid legal foundation for international offsets. Any effort to include international offsets in federal CAA GHG regulation would therefore have to be based on tenuous and untested legal theories.

\section{A. Traditional-Style Offsets: Permitting and the NAAQS}

The existing offset program under permitting schemes (PSD and New Source Review (NSR)) in the CAA would provide the strongest precedential foundation for a GHG offset program. Unfortunately, there appears to be no legal basis for an internationalization of this program. ERCs can only be created when emissions are reduced by a source in a nonattainment area. Reductions in emissions from foreign sources therefore could never qualify for ERCs—-foreign countries

57ce35/1fde15e82ad9cb50852564ec007aa24e!OpenDocument (last visited June 19, 2010).

12. CAA $\$ 173(\mathrm{c})(1)$. The only exception is where another nonattainment area has equal or higher levels of the relevant pollutant and emissions from that other area contribute to the nonattainment status of the area where the ERC was created. For the primarily local pollutants regulated under the NAAQS, this in practice means that ERCs can only be used where they are created or in nearby or upwind areas. 
cannot be out of attainment with respect to U.S. national air quality standards.

There are also significant conceptual and practical problems with regulation of GHGs under the NAAQS (as would be required for any areas to be in nonattainment and therefore eligible for use of ERC offsets). Few who have studied CAA GHG regulation favor a NAAQS approach. Among the largest of these conceptual problems is that the globally uniform nature of GHG pollution would require the entire United States to be either in attainment or nonattainment, and that, as a result, different rules for attainment and nonattainment areas would have little meaning.

If GHGs were regulated under the NAAQS and the standard set at a level placing the entire United States in nonattainment, some nationwide offsetting would be possible. Emissions of GHGs from any area would affect compliance with the NAAQS everywhere else in the country due to atmospheric mixing of GHGs, and any additional reductions in GHG emissions would therefore qualify for ERCs that could be used anywhere in the country. Although this would undoubtedly be useful, it does nothing to allow the use of international offsets. As mentioned above, areas outside the United States cannot be in nonattainment, even if their emissions contribute to U.S. concentrations. In this respect, the CAA is designed to deal with local or at most national pollution problems — not global pollutants like GHGs.

If GHGs were not regulated under the NAAQS, or the NAAQS set at a level that put the entire United States in attainment, permitting requirements would still exist but be subject to a different standard. All stationary sources that emit pollutants regulated under the CAA are subject to NSR when they are initially built or undergo major modification. ${ }^{13}$ Outside of nonattainment areas, this permit requires the use of best available control technology (BACT). ${ }^{14} \mathrm{EPA}$ is charged with determining whether a facility seeking a permit has implemented BACT. This determination is case-by-case, but is guided by a "clearinghouse" set up by EPA to provide information on technologies that meet BACT and other standards required in the CAA. ${ }^{15}$

Could EPA define BACT so as to include international offsets? If so, no NAAQS regulation would be necessary (at least for offsets to be brought into CAA regulation). Unfortunately, the answer seems to be no. BACT is defined in the CAA as:

[A]n emission limitation based on the maximum degree of reduction of each pollutant subject to regulation under this chapter emitted from or which results from any major emitting facility, which the permitting authority ... determines is achievable for such facility through application of production processes and available methods, systems, and techniques, including fuel cleaning, clean fuels, or treat-

13. CAA $\$ 165(\mathrm{a})$

14. CAA $\$ 165(\mathrm{a})(4)$.

15. U.S. EPA, RACT/BACT/LAER Clearinghouse (RBLC), http://cfpub.epa. gov/RBLC/ (last visited June 20, 2010). ment or innovate fuel combustion techniques for control of each pollutant. ${ }^{16}$

There are two ways in which this definition appears to block incorporation of offsets into BACT. First, the language strongly implies that BACT is a purely technological standard. References to "processes ... methods, systems, and techniques" and the specific examples given (such as "fuel cleaning") indicate that technology, not trading or offsetting, is to be the basis of BACT. One might argue that offsets are a "method" or a "system" of controlling emissions, but this may stretch the meaning of these terms beyond their breaking point in the context of the statute.

A larger problem for offsets is the apparent requirement that BACT must control emissions from the facility seeking a permit. BACT is defined as being based on reductions in emissions of pollutants "emitted from ... any major facility" that EPA determines is "achievable for such facility." Reductions in emissions at other facilities appear to be explicitly excluded.

One possible way to escape this requirement stems from the fact that BACT is not a specific requirement that a given technology or "method" be implemented, but a standard based on the emissions reductions that identified technologies make possible. Even if offsets cannot be considered when BACT is set, therefore, it might be possible for them to be considered in determining whether BACT is met. There is no apparent precedent for this, however. If it were legal, one would expect domestic offsetting programs under BACT for pollutants already regulated under the CAA, and no such programs exist.

Finally, even if international offsets could be used to fulfill NSR requirements, new and modified facilities would still face requirements under CAA NSPS. For reasons discussed in the next section, it appears unlikely that offsets could be used under NSPS regulation. NSR offsets might therefore have limited value, even if they could be legally implemented.

\section{B. Offsets Under CAA Performance Standards}

Given the problems mentioned above with regulation of GHGs under the NAAQS program, most (but not all) who have studied the issue appear to favor regulating GHGs under the NSPS. NSPS GHG regulation is explicitly funded under President Barack Obama's proposed fiscal year 2011 budget. $^{17}$ Under the NSPS, EPA is charged with dividing emitters into "source categories" and creating performance standards for new and modified sources within the category. ${ }^{18}$ The Agency is further charged under $\$ 111(\mathrm{~d})$ of the CAA with creation of guidelines under which states implement performance standards for existing sources. ${ }^{19}$ The remainder of this section

16. CAA $\$ 169(3)$.

17. See Office of Mgmt. \& Budget, Budget of the United States GovernMENT: FisCal Year 2011, at 126 (2010), available at http://www.whitehouse. gov/omb/budget/fy2011/assets/environmental.pdf (stating: "The Budget also requests $\$ 7$ million to develop New Source Performance Standards to control GHG emissions from a few categories of major stationary sources.").

18. CAA $\$ 111$.

19. CAA $\$ 111(\mathrm{~d})$. 
discusses the permissibility of international offsets within federal NSPS regulation-offsets under state regulation of existing sources will be discussed below.

Traditionally, the NSPS have been technological standards, requiring emissions sources to implement "adequately demonstrated" technologies or take other measures to achieve an equivalent reduction in emissions. ${ }^{20}$ This would superficially appear to rule out offsets or indeed any marketbased approach under the NSPS - the standards appear to be traditional command-and-control regulation. This view may not be entirely accurate, however. The CAA defines "standard of performance" as "a standard for emissions of air pollutants which reflects the degree of emission limitation achievable through the application of the best system of emission reduction ... . which the Administrator determines has been adequately demonstrated." 21 Might "best system of emission reduction" be interpreted to mean, for example, an emissions trading system or offsets?

There is precedent for this understanding of the definition. At least one emissions trading system, for waste incinerators, has been implemented under the NSPS. ${ }^{22}$ EPA also planned to create a trading scheme for mercury emissions in its Clean Air Mercury Rule. ${ }^{23}$ That rule was struck down by courts on other grounds. ${ }^{24}$ EPA therefore believes that emissions trading is permissible under the NSPS despite the foundations of the program in technology standards. If the statutory language is flexible enough to permit this interpretation, would it also allow inclusion of a system for international offsets?

This is an untested legal question, but the best answer appears to be "maybe, but probably not." At minimum, implementing an international offset program through NSPS regulation is legally risky. Looking beyond the relatively ambiguous "best system of emission reduction" language in the definition, other language in $\$ 111$ more clearly indicates that the NSPS are intended to be technologically driven. The section refers repeatedly to "technological system[s] of emissions reduction" as the basis of NSPS standards, a term clearly defined in the statute as (not surprisingly) a technological standard - examples given in the statute are "precombustion cleaning or treatment of fuels" and the like. ${ }^{25}$ This language, combined with the traditional implementation of NSPS standards in technological terms, make exploitation of the ambiguity in the best system of emission reduction definition to allow for implementation of nontechnological control methods such as offsets legally difficult. Complicating the issue further, "standard of performance" is given a different definition elsewhere in the CAA that does not include

20. CAA $\$ 111(\mathrm{a})(1)$.

21. Id.

22. See 40 C.F.R. $\$ 60.33$ b(d)(2) (2009) (stating: "A State plan may establish a program to allow owners or operators of municipal waste combustor plants to engage in trading of nitrogen oxides emission credits. A trading program must be approved by EPA before implementation.").

23. See U.S. EPA, Clean Air Mercury Rule: Basic Information, http://www.epa. gov/mercuryrule/basic.htm (last visited June. 20, 2010) (stating: "The Clean Air Mercury Rule established a cap-and-trade system for mercury that is based on EPA's proven Acid Rain Program.").

24. New Jersey v. EPA, 517 F.3d 574, 578, 38 ELR 20046 (D.C. Cir. 2008).

25. CAA $\$ 111(\mathrm{a})(7)$. the ambiguous best system of emission reduction language (though it does not explicitly require technological standards either). ${ }^{26}$ Courts are therefore likely to carefully scrutinize EPA attempts to broadly interpret $\$ 111 .{ }^{27}$

To some extent, this argument against offsets being permissible under NSPS regulation proves too much-if taken to its logical conclusion, a narrow reading of the definition of "standard of performance" forbids not only the use of offsets but of emissions trading programs (of which at least one example exists). This existence of regulatory (though not legal) precedent is helpful to future efforts to create emissions trading programs under NSPS regulation; however, there is no such precedent for offsets, though trading and offsets are conceptually similar in many respects. ${ }^{28}$ International offsets present a further problem in that international emissions sources are not mentioned at all in $\$ 111$ - there is similarly no precedent for any consideration of international emissions in NSPS programs. While the legal issues are complex and impossible to predict with certainty, it appears unlikely that an EPA effort to incorporate international offsets into NSPS GHG regulation would survive challenge in court. It cannot be ruled out, however, and at least stands a chance of being permissible.

\section{Offsets Under More Speculative CAA Programs}

Some have proposed regulating GHGs under rarely used sections of the CAA that, due to their brevity, may provide EPA with greater regulatory discretion. The two CAA sections most often proposed are $\$ 115,{ }^{29}$ governing international emissions, and $\$ 615,,^{30}$ part of the CAA's Title VI provisions aimed at pollutants that damage the ozone layer. The chief attraction of regulating GHGs under these provisions, as opposed to the much more detailed provisions governing CAA programs like the NSPS and

26. CAA $\$ 302(1)$.

27. This is a complicated issue of statutory interpretation and results are difficult to predict. For more analysis of interpretations of the relevant language in the related context of whether emissions trading is permitted under the NSPS, see Nathan Richardson et al., Greenhouse Gas Regulation Under the Clean Air Act: Structure, Effects, and Implications of a Knowable Pathway (Resources for the Future, RFF Discussion Paper No. 10-23, 2010). See also Inimai M. Chettiar \& Jason A. Schwartz, Inst. for Policy Integrity, The Road Ahead: EPA's Options and Obligations for Regulating Greenhouse Gases (2009), available at http://policyintegrity.org/files/publications/TheRoadAhead.pdf.

28. As discussed in the text, there appears to be no case law indicating whether the statutory language of the CAA permits NSPS regulation with emissions trading. There is nevertheless practical precedent for the practice, created by the program for waste incinerators discussed above (see note 22 and accompanying text). While the Clean Air Mercury Rule was invalidated by the U.S Court of Appeals for the District of Columbia Circuit on other grounds (see supra notes 23 and 24 and accompanying text) and therefore did not create an actual regulatory program, the Agency's inclusion of trading mechanisms under the NSPS indicates, at least, that it believes they are within the latitude granted by the statute. Use of offsets under the NSPS also has no precedent in case law, but in contrast to emissions trading, has no apparent precedent in either actual regulatory programs or proposed rules.

29. See Roger Martella \& Matthew Paulson, Regulation of Greenhouse Gases Under Section 115 of the Clean Air Act, Daily Env't Rep., Mar. 9, 2009, at 5, available at http://www.sidley.com/files/Publication/c789bb2a-7562-4149-8474036f21dee348/Presentation/PublicationAttachment/3a6fe43a-22d1-47159f69-04c17efdbd00/GreenhouseGases.pdf.

30. See Regulating Greenhouse Gas Emissions Under the Clean Air Act, 73 Fed. Reg. 44354, 44519 (proposed July 30, 2008). 
NAAQS that are actually in use, is the fact that they have almost none of the restrictions, definitions, and requirements that limit EPA discretion.

Using $\$ 115$ or $\$ 615$ as the primary vehicle for GHG regulation under the CAA might allow EPA to incorporate international offsets into GHG regulation-there is little in these CAA provisions to prevent it. The problem with general regulation under these provisions is that it is legally untested and likely to be viewed by courts with skepticism. As I have written elsewhere, such sweeping regulation under $\$ 115$ (or \$615) may not be legal. ${ }^{31}$ Courts usually disfavor attempts by agencies to use short, vague statutory language to justify sweeping regulatory changes. As Justice Antonin Scalia has put it: "Congress does not ... hide elephants in mouseholes." 32 Such broad regulation of GHG emissions under $\$ 115$ (indeed, any GHG regulation under the CAA) is highly likely to be challenged in the courts. The same brevity in the section that grants EPA the desired regulatory flexibility will be a weak point, likely a fatal one, in such a challenge. In other words, the same lack of specificity that allows EPA to include offset provisions in regulation under these sections makes such regulation legally questionable.

A different but related approach would be to regulate GHGs primarily under more established sections of the CAA, such as $\$ 110$ (NAAQS) or $\$ 111$ (NSPS), but to use $\$ 115$ as a vehicle for international aspects of GHG regulation, potentially including offsets. Section 115 allows EPA broad discretion to instruct states to regulate emissions when domestic regulation is insufficient to prevent harm to foreign countries. ${ }^{33} \mathrm{EPA}$ might therefore conclude that, even after domestic GHG regulation under $\$ 110$ or $\$ 111$, other countries are still at risk and use $\$ 115$ to impose additional regulatory requirements on states. The lack of specificity in $\$ 115$ discussed above might allow EPA to include international offsets in any such scheme.

This approach is more legally plausible than general GHG regulation under $\$ 115$. First, the scale of regulation under $\$ 115$ is smaller. EPA would not be attempting to create an economywide GHG regulatory program under a four-paragraph, never-used section of the statute, but rather using that section as the basis for one or a few components of a larger program justified elsewhere in the statute. Second, those parts of the program that did fall under $\$ 115$ would seem to fit better with the stated subject of that section-international air pollution.

Significant problems would remain, however, that make this approach legally suspect. First, there is some tension between the language of $\$ 115$ and offsets themselves. Section 115 is aimed at reductions in "pollutants emitted in the United States [that] cause or contribute to air pollution which may reasonably be anticipated to endanger public health or welfare in a foreign country." ${ }^{4}$ Offsets generally

31. See Richardson et al., supra note 27.

32. Whitman v. Am. Trucking Ass'ns, Inc., 531 U.S. 457, 468, 31 ELR 20512 (2001).

33. CAA $\$ 115(\mathrm{~b})$. The foreign country must also grant the United States reciprocal rights.

34. CAA $\$ 115(\mathrm{a})$. would have the opposite effect-they would allow states to export emissions (and, therefore, endangerment) to foreign countries. This is less true for GHGs since they are uniformly distributed globally-to the extent that offsets would result in lower global emissions, foreign countries would benefit just as much as the state in which the offset is used. Still, offsets would not result in any reduction in "pollutants emitted in the United States" and therefore seem at odds with the plain language of $\$ 115 .{ }^{35}$

The second problem is that courts may view an international offset program as an "elephant in a mousehole" just as they likely would a general GHG regulatory program. The former is smaller and less complex, to be sure, but is still likely to involve substantial new regulation and creation of a large international offset market. Section 115 may not provide sufficient legal basis on which to ground such a regulatory scheme.

The chief advantage of regulating GHGs primarily under well-tested provisions of the CAA and restricting the use of $\$ 115$ to offsets is not, therefore, that the legal foundation for use of offsets or use of $\$ 115$ for any GHG regulation are significantly stronger, but that these questions can be separated from the broader GHG regulatory scheme. If a court rules that $\$ 115$ cannot be used in this way, the remainder of the GHG regulatory scheme can stand alone-though it would be more expensive.

\section{Offsets as State-Level CAA Regulation}

The previous sections have dealt with federal regulation under the CAA. CAA programs and enforcement are not restricted to EPA or the federal government generally, however. The largest programs within the CAA for stationary source regulation, the NSPS and NAAQS, have substantial state-level components, and the CAA is generally viewed as an exercise in "cooperative federalism." State governments do not face many of the restrictions placed on EPA by the CAA and separation-of-powers doctrines, and have substantial flexibility to implement policies to meet (or exceed) CAA requirements. It is therefore worth exploring whether states operating under the NAAQS or NSPS would be able to include international offsets in their component of CAA GHG regulation.

\section{A. State Regulation Under the NAAQS}

Under the NAAQS, states are responsible for creating state implementation plans (SIPs) that detail how state regulatory efforts will result in air quality that meets or exceeds the national standards. EPA must evaluate these plans and may approve or reject them-only if an SIP is rejected can EPA directly implement regulation through a federal implementation plan (FIP). The Agency can also make "SIP calls" in which it requests revisions of existing SIPs. EPA can make

35. This would not necessarily be an issue with a GHG regulatory scheme entirely under $\$ 115$ authority, as such a scheme would presumably result in reductions in U.S. emissions, even if $\$ 115$ 's flexibility allowed offsets to be included. 
recommendations and retains final approval authority over SIPs, but cannot dictate the regulatory policies that states implement beyond determining whether they fulfill the requirements of the CAA. This process has in the past been a vehicle for integration of emissions trading schemes into NAAQS regulation, with EPA issuing a "model" set of regulations that states may then implement in their SIPs. ${ }^{36}$ The practical result is a full emissions trading program under the NAAQS, but it is states, not EPA, that actually implement the program. EPA could only directly implement a NAAQS program if it rejects states' SIPs and instead implements an FIP. ${ }^{37}$

In principle, it would likely be possible for EPA to include international offsets in a model rule for states. Section 110(a) (2)(A) of the CAA lists regulatory mechanisms that states can use in their SIPs: "Enforceable emissions limitations and other control measures, means, or techniques (including economic incentives such as fees, marketable permits, and auctions of emissions rights)." 38 This language appears to be sufficiently broad to encompass offsets. Offsets could easily be characterized as a "control measure[ ], means, or technique[ ]", and the mention of "economic incentives" seems to indicate that Congress intended to give broad flexibility to the states. On the other hand, some such economic incentives are mentioned, while offsets are not. The list is not exclusive, however. Certainly it is much easier to fit offsets into this statutory language than it is to characterize them as "performance standards" under the NSPS.

If EPA did explicitly include offsets in a model SIP (and, in principle, even if it did not), states could then choose whether to include offset provisions in their SIPs. If offsets were part of a model rule, states would know that if they followed the model (including use of offsets), their SIPs would be approved. A problem with past use of market mechanisms in the SIP process has been the inability of EPA to guarantee that emissions in a given state would cause significant air pollution in another state, as courts have held is required by the CAA. ${ }^{39}$ This would likely not be an issue with offsets (international or otherwise) in the GHG context, however. Because GHGs are globally dispersed pollutants, any reduction in emissions anywhere should have the same effect on ambient GHG levels.

While legally plausible up to this point, this approach suffers from the same problems discussed in Section II.A. with respect to GHG regulation under the NAAQS - the program is not a good fit for the GHG problem, and the fact that states have some flexibility does not change that very

36. See, e.g., U.S. EPA, Clean Air Markets: $\mathrm{NO}_{\mathrm{x}}$ Budget Trading Program-Basic Information, http://www.epa.gov/airmarkets/progsregs/nox/sipbasic.html (stating that, under this program, "[c] ap and trade programs set a cap on overall regional emissions and allocate each affected source allowances authorizing a certain number of tons of emissions").

37. One scholar has proposed that EPA attempt to resolve some of the issues with a GHG NAAQS by rejecting all SIPs and implementing a single, nationwide FIP. See Jonathan B. Wiener, Think Globally, Act Globally: The Limits of Local Climate Policies, 155 U. PA. L. Rev. 1961, 1967 (2007).

38. CAA $\$ 110(\mathrm{a})(2)(\mathrm{A})$

39. North Carolina v. EPA, 531 F.3d 896, 908, 38 ELR 20306a (D.C. Cir. 2008) (per curiam). much. Just because states may be able to implement offsets or emissions trading does not solve larger problems such as the level at which a GHG NAAQS should be set or the futility of states being forced to plan to meet a standard for a global pollutant over which they have little individual control. As discussed in Section III.C. below, implementation of offsets through state regulation also may create more legal problems, some of them constitutional, than it resolves.

\section{B. State Regulation Under the NSPS}

As mentioned in Section II.B. above, EPA is charged under the CAA with regulation of new and modified stationary sources in the NSPS program, while states are charged with regulation of existing sources under $\$ 111(\mathrm{~d})$. Regulation under $\$ 111(\mathrm{~d})$ only comes into play if a pollutant is not regulated under the NAAQS or certain other CAA provisions. ${ }^{40}$ Assuming this is the case, $\$ 111(\mathrm{~d})$ regulation is similar in many ways to the NAAQS process: EPA creates "guidelines" for existing source performance standards, and states must create a plan for implementation of these standards. The Agency then approves or rejects the state plan.

Because of the way in which $\$ 111(\mathrm{~d})$ is written, however, it does not grant states the same degree of regulatory flexibility as the NAAQS/SIP process does. States are required by this section to regulate through "standards of performance," the same general method-defined in the statute-as EPA is directed to use. ${ }^{41}$ The ambiguity of this term's definition under the CAA is discussed in Section II.B. above, and the same analysis would apply to state regulation. As a result, prospects for integration of international offsets into statedriven $\$ 111(\mathrm{~d})$ regulation of existing sources seem no greater than those for such integration into NSPS programs generally.

\section{Other Issues Surrounding State Regulation}

While their quasi-sovereign status and the significant delegations of authority within CAA programs grant states greater regulatory flexibility, one must be careful not to ignore the restrictions that state law places on this flexibility. While states taken as a whole have great regulatory discretion, the same is true of the federal government. States only appear to have more discretion when compared to a single branch of the federal government or, as has been done in the sections above, with a single federal agency-EPA. In reality, SIPs, $\$ 111(\mathrm{~d})$ performance standards, and other air pollution regulation by states must be approved by state legislatures or state agencies with sufficient authority delegated to them. Implementing a given regulatory scheme, such as international offsets, faces similar legal and ultimately political challenges at the state level as it does at the federal level. Analysis of the legality of international offsets under state law is beyond the scope of this Article, but will ultimately be highly relevant if state regulation is to be the vehicle for integrating these offsets into larger CAA regulation.

40. CAA $\$ 111(\mathrm{~d})(1)(\mathrm{A})$.

41. Id. 
States also have the power to go beyond federal environmental regulation, as illustrated in the GHG context by California's AB 32 measures ${ }^{42}$ and regional initiatives such as the Regional Greenhouse Gas Initiative (RGGI). ${ }^{43}$ In principle, states acting alone or in groups could implement GHG regulation that includes provisions for international offsets. This is true regardless of the form and content of federal CAA regulation of GHGs, or even in the absence of any federal regulation. Analysis of this possibility is similarly beyond the scope of this Article, but it is nevertheless relevant and legally (if not necessarily politically or practically) realistic.

There is some potential that state regulations that incorporate international offsets, whether under delegated CAA authority or independent state authority, could be deemed to impermissibly interfere with the executive branch foreign affairs powers under the U.S. Constitution. How this issue would play out would depend on the specific facts of the dispute. States would be less likely to encounter constitutional problems if offsets can be characterized as contracts between private-party emitters, rather than as a treaty-like arrangement between a state and a foreign country. In general, however, this issue might never come before a court, as standing issues could present a significant barrier. ${ }^{44}$

\section{Conclusions}

There appears to be no solid legal foundation for incorporation of international offsets in CAA GHG regulation. Offsets might be brought in through state-level CAA regulation. Because $\$ 110(\mathrm{a})(2)(\mathrm{A})$ is the only CAA provision sufficiently broad to grant states the regulatory authority to incorporate offsets, the only offset-compatible CAA pathway open to EPA would be the NAAQS. This pathway is generally perceived as a poor fit for the GHG problem. Bringing in offsets through the more GHG-friendly NSPS program at either the federal or state (using $\$ 111(\mathrm{~d})$ ) level requires creative interpretation of CAA language (specifically, whether offsets are "standards of performance") that may not hold up in court. State efforts to integrate international offsets under delegated CAA authority also require authorization under state law, and may be subject to challenge on constitutional grounds. Other CAA programs, such as $\$ 115$, might allow EPA to implement offset programs without state involvement, but regulation of GHGs under these programs at all is legally suspect.

42. See California Air Resources Board, Assembly Bill 32: Global Warming Solutions Act, http://www.arb.ca.gov/cc/ab32/ab32.htm (stating that, among other mandates, the California Air Resources Board "shall prepare and approve a scoping plan for achieving the maximum technologically feasible and costeffective reductions in greenhouse gas emissions from sources or categories of sources of greenhouse gases by 2020 ").

43. See RGGI, Regional Greenhouse Gas Initiative Model Rule (2008), available at http://www.rggi.org/docs/Model\%20Rule\%20Revised\%2012.31.08. pdf.

44. This question-whether unilateral state action to permit international offsets interferes with the executive foreign affairs power-is complex, and a full analysis is beyond the scope of this Article.
As a result, it appears that new federal or at least state legislation is required to incorporate international offsets into U.S. GHG regulation. Use of offsets - and the cost savings they would likely bring-should therefore be considered a major advantage of comprehensive climate legislation over the CAA tools currently available to EPA. 